\title{
A Resilience Toolbox and Research Design for Black Sky Hazards to Power Grids
}

\author{
Dmitry Borisoglebsky (iD ${ }^{1}$ and Liz Varga ${ }^{2}{ }^{2}$ \\ ${ }^{1}$ School of Management, Cranfield University, Bedford MK43 OAL, UK \\ ${ }^{2}$ Department of Civil, Environmental \& Geomatic Engineering, UCL, London WC1E 6BT, UK \\ Correspondence should be addressed to Liz Varga; l.varga@ucl.ac.uk
}

Received 25 January 2019; Accepted 12 May 2019; Published 9 June 2019

Guest Editor: Seyedmohsen Hosseini

Copyright (c) 2019 Dmitry Borisoglebsky and Liz Varga. This is an open access article distributed under the Creative Commons Attribution License, which permits unrestricted use, distribution, and reproduction in any medium, provided the original work is properly cited.

\begin{abstract}
A structured collection of tools for engineering resilience and a research approach to improve the resilience of a power grid are described in this paper. The collection is organized by a two-dimensional array formed from typologies of power grid components and business processes. These two dimensions provide physical and operational outlooks, respectively, for a power grid. The approach for resilience research is based on building a simulation model of a power grid which utilizes a resilience assessment equation to assess baseline resilience to a hazards' profile, then iteratively selects a subset of tools from the collection, and introduces these as interventions in the power grid simulation model. Calculating the difference in resilience associated with each subset supports multicriteria decision-making to find the most convenient subset of interventions for a power grid and hazards' profile. Resilience is an emergent quality of a power grid system, and therefore resilience research and interventions must be system-driven. This paper outlines further research required prior to the practical application of this approach.
\end{abstract}

\section{Introduction}

Power grids play an important role for modern society [1]. A failure in a power grid demonstrates a lack of engineered and engineering resilience to one or more hazards. A failure in a power grid may result in follow-up failures in the grid and other infrastructures [2]. Bo et al. [3] mapped and summarized 23 major blackouts from 1965 to 2012, representing major failures in power grids. Among the surveyed literature, no additional major blackouts were found, which is partially validated by the list of billion-dollar weather and climate disasters [4] in the US. Statistical studies show that major outages happen more often than can be concluded from statistics on minor and intermediate outages $[5,6]$.

Therefore, according to theoretical distributions and history of disasters, the world will experience major outages in the future. The probability of an outage in a specific power grid may be reduced by the application of resilience research to improve the resilience of power grid infrastructures.

This paper describes an approach for resilience research to improve the resilience of a power grid. It is based on mapping existing tools for resilience enhancement in a matrix-based classification for the follow-up targeted resilience research. This paper is limited by the tools arising in the literature review and so does not provide the complete list of existing tools. The literature does not provide a way to rank the tools for their effectiveness so no prioritization is available.

\section{Methods}

Literature review was performed to identify academic articles according to two schemas: functional and summary. The functional schema facilitated the search for tools for resilience enhancement, definitions of resilience, and experience of blackouts. The summary schema enabled the identification of summaries and reviews of resilience assessment frameworks.

Search strings for advanced search in Scopus database are shown in Table 1. The primary focus of this article is to identify and classify the tools for resilience enhancement. Other search topics provide context. 
TABLE 1: Strings for search queries run in Scopus database.

\begin{tabular}{|c|c|c|}
\hline Schema & Topic & Query \\
\hline Functional & Resilience & $\begin{array}{l}\text { TITLE }((\text { resilien } *) \text { AND }(\text { electric } * \text { OR power } *)) \text { OR KEY }(\text { ( resilien } *) \\
\text { AND }(\text { electric } * \text { OR power } *))\end{array}$ \\
\hline Functional & Blackout & $\begin{array}{c}\text { TITLE ( ( blackout* OR outage } * \text { ) AND ( electric } * \text { OR power } *) \text { ) OR KEY } \\
\text { ( ( blackout } * \text { OR outage } * \text { ) AND ( electric } * \text { OR power } *))\end{array}$ \\
\hline Summary & Framework & $\begin{array}{l}\text { TITLE ( resilien* AND ( measur* OR assess* OR indicat* OR quant* OR } \\
\text { metric*) AND (review OR overview OR survey OR state ) ) }\end{array}$ \\
\hline
\end{tabular}

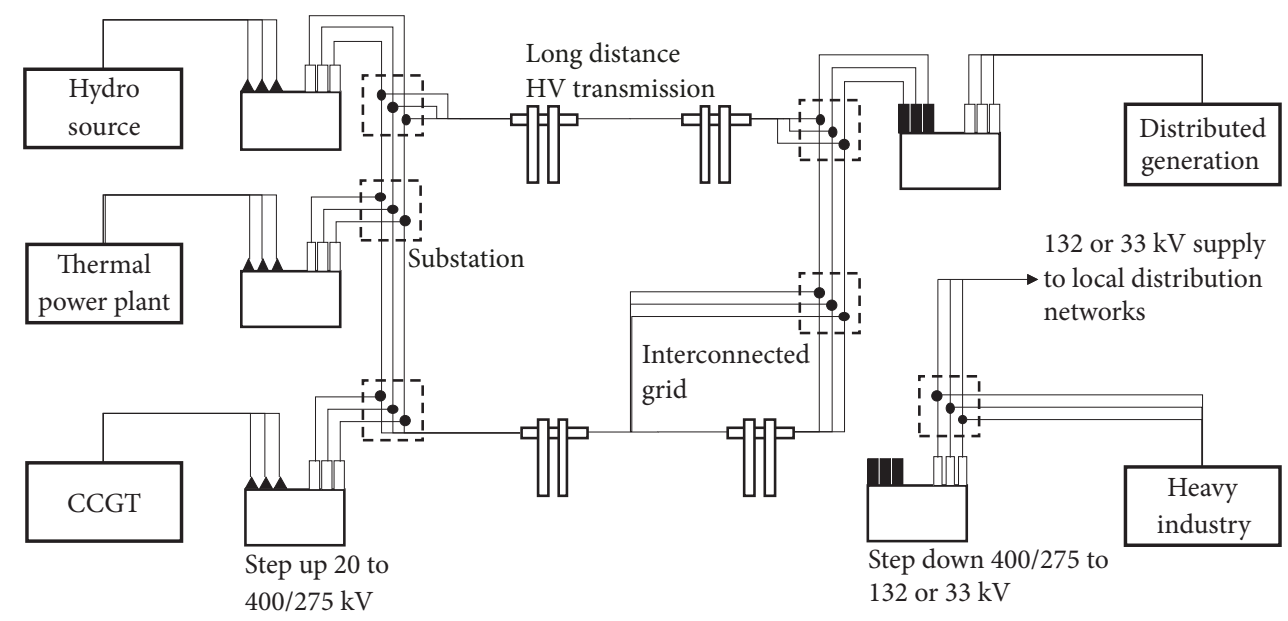

FIGURE 1: Generation and transmission network (UK voltages and practice) [7].

The functional review assumes that the search strings provide source papers for an incomplete yet sufficient study coverage of the topics. The functional search queries selected source papers based either on matching titles (TITLE) or on keyword values (KEY). SCOPUS allows an advanced search producing a search engine results page with a set of tools for filtering on the left panel. Using the database's filtering capabilities, the initial list of results was cleared of nonEnglish (e.g., German or Chinese), non-article (a peer-review is expected for most articles), and irrelevant topics (e.g., medicine or biology). The toolbox cites 54 papers, reduced from 174 papers.

The summaries' review assumes that a reasonably complete review of resilience assessment frameworks, for the purpose of this research, is possible via study of existing review papers on this topic. Papers for review were selected by the relevance of their titles and abstracts.

\section{Results}

3.1. Power Grid. A power grid is a system that produces, transports, and consumes electrical energy. Generators convert fuels and other energy sources into electrical power. Stepup and step-down transformation stations border transmission lines with substations in between. The UK power grid uses several voltages with $400 / 275 \mathrm{kV}$ in the transmission grid and $132 / 33 \mathrm{kV}$ in distribution grids, similar architecture in other countries. Accompanied by visualization (see Figure 1), components of a power grid are listed below: (i) Producer is a part of a power grid that produces electrical energy regardless of the amount of energy or stability of production. A hydropower plant, fossilfuel plant, wind generator farm, and a microgrid are examples of producers of electricity.

(ii) Step-up/down substation is required to transform current, e.g., from a producer's $20 \mathrm{kV}$ to $400 / 275 \mathrm{kV}$ of transition grid and from $400 / 275 \mathrm{kV}$ to $132 / 33 \mathrm{kV}$ of distribution grid.

(iii) Power line is an overhead or underground electricity transmission line.

(iv) Substation is a station that transitions and controls the power flow.

(v) Consumer is a part of a power grid that consumes electrical energy regardless of the amount of energy or stability of consumption. A factory, a distribution grid, and a microgrid are treated as consumers of electricity.

(vi) Control is a hardware, software, or organizational part of a utility company. While control is not shown in Figure 1, it is a critical part of a power grid.

3.2. Hazards. Mukherjee et al. [9] analyzed billion-dollar blackouts in the US between 2000 and 2016, while Bie et al. [10] provided statistics on of the major blackouts in the world. While the lists of causes are slightly different, there is a major difference in the distributions of blackouts by causes between these two regions (see Table 2). For both the 
TABLE 2: Causes of major blackouts in the USA and the world.

\begin{tabular}{lccc}
\hline USA & & The world & \\
\hline severe weather & $52.9 \%$ & equipment failure & $47.8 \%$ \\
intentional attack & $22.9 \%$ & natural disasters & $30.7 \%$ \\
system operability disruption & $10.3 \%$ & malfunctions/ miscellaneous & $10.1 \%$ \\
public appeal & $4.2 \%$ & vandalism & $5.7 \%$ \\
equipment failure & $4.0 \%$ & supply shortage & $4.3 \%$ \\
fuel supply emergency & $3.1 \%$ & cyber attack & $1.4 \%$ \\
islanding & $2.6 \%$ & & \\
\hline
\end{tabular}

US and world the first three causes are responsible for over $85 \%$ of blackouts, $86.9 \%$, and $88.67 \%$ respectively. Additional research is required to explain the difference in causes and magnitudes.

Type and intensity are the basic characteristics of hazards when considering the resilience of engineered systems such as a power grid. Type, e.g., precipitation, earthquake, and intensity, e.g., $300 \mathrm{~mm}$ in 24 hours, 4 Richter scale, differ greatly but can have similar effects, e.g., outage of a power grid component. The impact of a hazard is at least infrastructure-, technology-, and asset-specific. Hazards and their likelihoods are specific to geographic regions, so despite both being island nations, the likelihood of earthquakes is much smaller in the UK than in Japan. A country-specific hazards' profile must be addressed during resilience research and for engineering the resilience of a national power grid. For example, National risk register of civil emergencies, 2017 edition [11] contains a list of hazards for the UK. An analysis of global risks [12] is annually produced by the World Economic Forum, Black Sky hazards [13] were defined by Electric Infrastructure Security Council, and academia also produces lists of hazards [14].

3.3. Resilience. In 2015, Fisher [15] mentioned the existence of 70 definitions for resilience, although a list and analysis of definitions were absent. 42 instances of definitions for resilience were collected during literature review. These were grouped by similarity and the group selected for this black sky study was the one to include definitions from governmental or international organizations likely expressing the need for strategic decision-making, such as the US White House [16], the UK Cabinet Office [17], or the UN Office for Disaster Risk Reduction (UNISDR) [18].

The definition by UNISDR [18] is selected for this paper, resilience is the ability of a system, community, or society exposed to hazards to resist, absorb, accommodate to, and recover from the effects of a hazard in a timely and efficient manner, including through the preservation and restoration of its essential basic structures and functions. The intended meaning is expressed in the analysis below.

This definition lists abilities, e.g., resist, recover; however it does not provide a rationale for the completeness of this list. This definition states that this ability belongs to an entity, e.g., system; we treat the power grid infrastructure as a 'system'. This definition states that that resilience is a function of hazards. This definition also states that resilience is conditional, e.g., exposed to hazards, effects of a hazard, and suggests either a secondary condition or an insight how resilience should be measured, via timely and efficient manner. Resilience is manifested via preservation and restoration of essential basic structures and functions, noting that not all the entity's elements need to be restored

From the literature, the following assumptions, abstractions, and explications were made for this paper, namely,

(i) A system has a normal and a disrupted state; a hazard changes a normal state of a system to a disrupted state. Resilience is the ability of an entity to execute the opposite transition, namely, from a disrupted state to a normal state, or to prevent a transition into a disrupted state.

(ii) A shorter time period in a disrupted state indicates a more resilient system, as is the ability to make a faster transition from a disrupted state to a normal state. Also, limited disruption to critical parts of the entity and fast recovery of critical parts reflects greater resilience to the scale of disruption caused by hazards.

(iii) Infrastructure is a complex system constructed from many alternative assets utilizing different technologies that work on different physical principles. For the purposes of this paper we assume a predetermined power grid configuration. Therefore, the manifestation of resilience is the preservation or recovery of basic functions. Basic functions are available to the customers in volume through time in locations.

(iv) Time, volume and location are possible input data for resilience assessment although location is mostly disregarded in this paper as it is focused on resilience of a whole infrastructure instead of its parts and the lack of theoretical means to address physical and likely multilayered virtual subgrids.

In a normal state, an infrastructure delivers a normal volume of basic functions, while an infrastructure in a disrupted state, in comparison to expected delivery in a normal state, delivers a reduced volume. A normal output is delivered by an infrastructure working in normal conditions, while the same infrastructure under a pressure of a hazard delivers a smaller volume. The nearer the volume to the normal output volume under pressure by a hazard, the greater the resilience, and the smaller the difference between the outputs; see Figure 2.

3.4. Resilience Assessment. Hosseini et al. [19] provide a classification of approaches to resilience assessment. The 


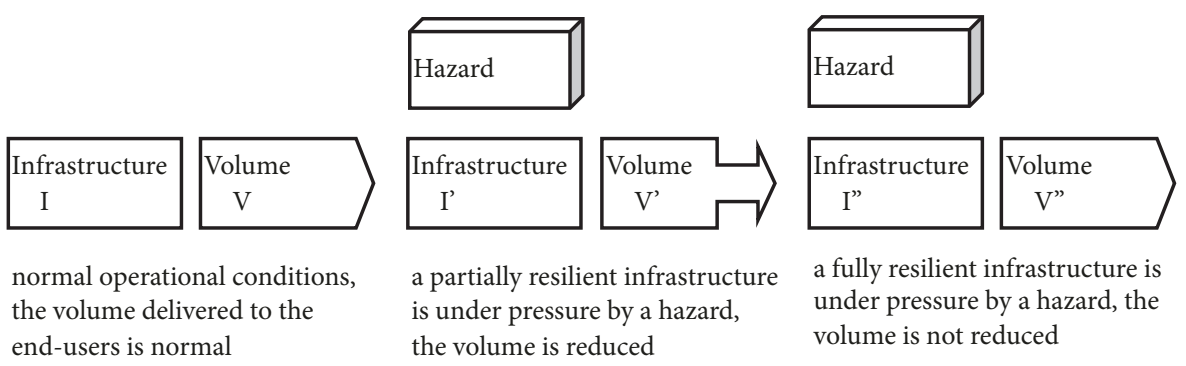

FIGURE 2: Three simplified hypothetical scenarios on the delivered volume in normal and disrupted states.

TABLE 3: Mathematical and conceptual representation of volume, time, and volume-over-time frameworks. 'R' means resilience value, ' $f$ ' and ' $\rho$ ' mean failure and recovery ratio, ' $v$ ' and ' $\mathrm{t}$ ' mean volume and time, and ' $\mathrm{D}(\mathrm{t})$ ' and ' $\mathrm{U}(\mathrm{t})$ ' mean disturbed and undisturbed delivery value at a time; encodings for subscripts, 'd' for disaster, 'e' for the lowest delivery, ' $n$ ' for normalization, and 'o' and 'c' mostly technical indicators of the opening and closing the chart.

\begin{tabular}{lcc}
\hline Branch & Equation & Conceptualization \\
\hline Volume & $R=\frac{v_{n}-v_{e}}{v_{n}}$ & $\begin{array}{c}\text { impact on performance } \\
\text { baseline performance } \\
\text { Time }\end{array}$ \\
& $R=\frac{t_{d}-t_{o}+f\left(t_{e}-t_{d}\right)+\rho\left(t_{n}-t_{e}\right)}{t_{d}-t_{o}+\left(t_{e}-t_{d}\right)+\left(t_{n}-t_{e}\right)}$ & $R=\frac{\text { weighted time period }}{\text { time period }}$ \\
Volume over time & $f=\frac{\int_{t_{d}}^{t_{e}} D(t) d t}{\int_{t_{d}}^{t_{e}} U(t) d t}, \rho=\frac{\int_{t_{e}}^{t_{n}} D(t) d t}{\int_{t_{n}}^{t_{n}} U(t) d t}$ & disturbed deliverey \\
& $R=\frac{\int_{t_{d}}^{t_{n}} D(t) d t}{\int_{t_{d}}^{t_{n}} U(t) d t}$ & undisturbed deliverey \\
\hline
\end{tabular}

general measure approach is used in this study because it is quantitative and generic. Yodo and Wang [20] listed quantitative resilience assessment frameworks for engineering systems, and this is used as the initial source of 'general measure' approaches.

A system produces output over time, which can be visualized via an area chart with volume on $\mathrm{Y}$ axis and time on $\mathrm{X}$ axis. This generates three main branches of resilience assessment, namely, (i) volume-focused that utilizes Y axis, (ii) time-focused that utilizes $\mathrm{X}$ axis, and (iii) volume-overtime-focused that utilizes X and Y axes. Most frameworks in Yodo and Wang [20] paper belong to this category.

Quantitative resilience assessment frameworks use mathematical equations. For the ease of understanding the idea behind a branch and an equation, representative examples were selected from Yodo and Wang's paper. Volume-focused framework is referring to [21], time-focused is referring to [22], and volume-over-time is referring to [23]. The corresponding mathematical equations are listed in Table 3 , while Figure 3 provides a supplementary visualization.

3.5. Business Processes. One or more organizations maintain a power grid and stable supply of electric energy. Just as a power grid may be described by components (see Figure 1, [7]), an organization may be described by business processes (see Figure 4, [24, 25]). The business processes of an organization influence the abilities of the organization to maintain the resilience of their products, in particular the operate business processes that focus on adding value to the customer. If operate processes are able to ensure that the power grid (the engineered system) is resilient, then the capabilities of people, technology, policies, and systems (the engineering system) that underpin these processes are resilient. Short descriptions [26] of business processes are provided below.

Manage processes consist of a subset of processes formulating organizations' vision and mission, methods to achieve those, and methods for effective utilization of resources. Set directions focus on formulating the vision and mission of the organization. Formulate strategies focus on identification and definition of strategies to reach the vision and mission. Direct business focuses on use of resources in actions to reach the vision and mission.

Operate processes consist of a subset of processes that deliver value to the customer. Develop product focuses on designing the product or service that would add value to the customer.

Get order focuses on finding customers and setting contracts with the customers. Fulfil order focuses on fulfilling the demand of the market. Support product process focuses on increasing value of the product or service.

Support processes consist of a subset of processes ensuring that operate processes are running. Manage finance focuses on having a sufficient cash flow. Support personnel focuses on ensuring sufficient human resources for operate and other processes. Manage technology focuses on creating an environment without bottlenecks due to a lack of technology.

Corporate learning focuses on increasing the quality of human resources. 


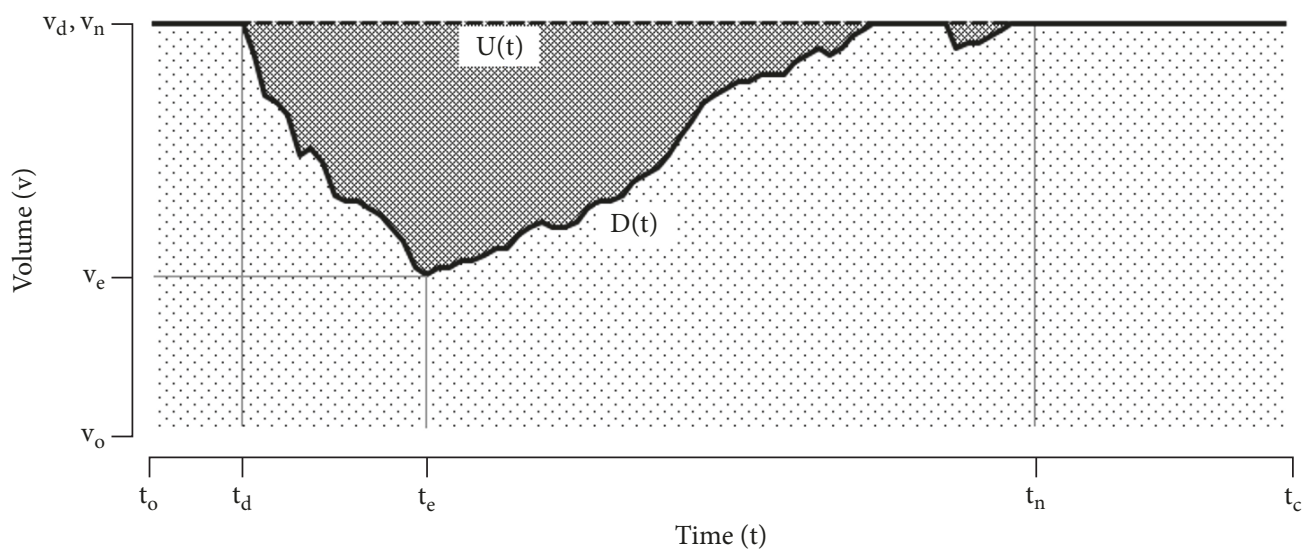

FIgURE 3: A disaster decreases the volume of delivery over time with the dark gray highlighting the impact of 'under-delivery' area, the solid black line (D) indicating the actual volume, and the dashed black line (U) indicating that the expected delivery would not make the disaster happen; encodings for subscripts, ' $d$ ' for disaster, ' $e$ ' for the lowest delivery, ' $n$ ' for normalization, and 'o' and 'c' mostly technical indicators of the opening and closing the chart.

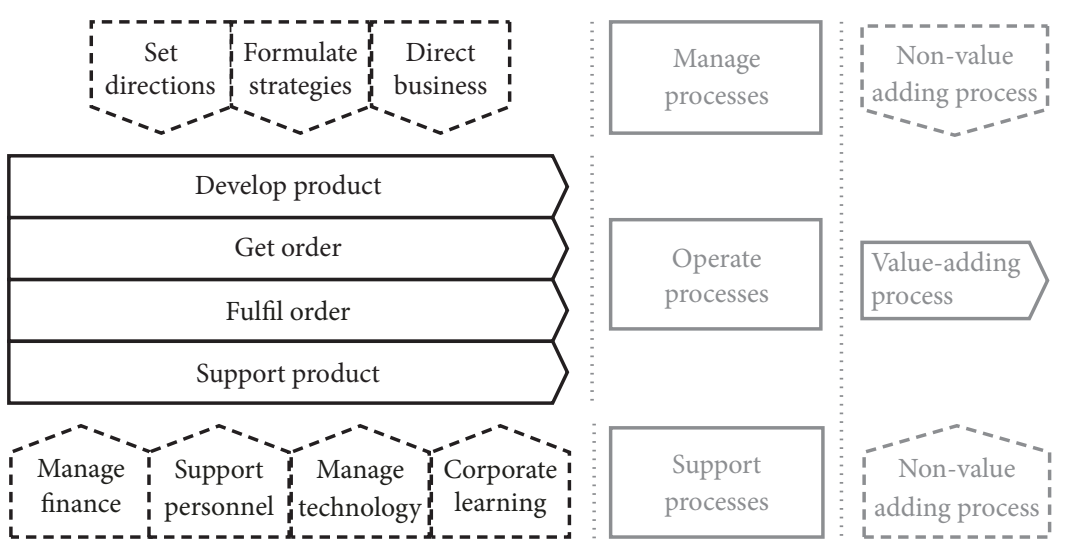

FIGURE 4: Business process architecture, redrawn from Bititci et al. [24, 25].

The criticality of the different classes of business process is not addressed; however, 'value-adding processes' have direct influence on operations. However some non-value adding processes, for example, manage technology, may have a direct bearing on the ability of operate processes to function.

3.6. Toolbox. Components of a power grid (see Figure 1) and business processes of an organization operating a power grid (see Figure 4) are sufficiently descriptive for high-level resilience modelling of a grid under operation. Together, these categories form a two-dimensional conceptual space. Tools to improve the resilience of a power grid may be assigned to relevant cells in the two-dimensional grid based on which component of the power grid and which business process are targeted by the tool. The tools identified in the literature review have been reviewed and allocated to the grid (see Table 4). A dash in a cell indicates that there is the absence of tools to improve resilience associated with the business process (row) and power grid component (column). Gaps may present opportunities for new tools to improve resilience or may indicate areas where resilience is either not a priority or has not yet been addressed.
Tools for improving resilience of a power grid are listed and briefly described below. These tools were suggested or mentioned in journal papers reviewed for this research. Names of these tools are taken from the papers with minor changes where needed to improve clarity. Tools are alphabetically ordered. The core idea of each tool is taken from its respective paper, and a short description is adjusted for the current paper or created when none is explicitly given. Each tool is described according to the following template: Name (abbreviation) [source] Short description. Statement on categorization.

Some of the tools are mentioned in multiple papers, yet usually a single citation is provided below indicating a reasonable reference. Because of the specifics of the literature review, it is assumed that the list of tools is sufficiently representative, yet it cannot be considered complete. Some tools are dependent on or are alternatives to other tools. This has not been addressed in the respective short descriptions. Another research may allocate tools into different categories, as a valid deductive or cogent inductive logical and ontological foundation have not been found nor created, and the current allocation is intuitive. 
TABLE 4: Index of tools for resilience enhancement of a power grid; tools are referred as abbreviations of their names.

\begin{tabular}{|c|c|c|c|c|c|c|}
\hline \multirow{2}{*}{ Process } & \multicolumn{6}{|c|}{ Component } \\
\hline & Producer & Substation & Power line & Substation & Consumer & Control \\
\hline Set directions & - & - & - & - & - & - \\
\hline Formulate strategies & - & RAT, RET & RAT, RET & RAT, RET & - & CP, OR, RAT, RET \\
\hline Direct business & IB & - & - & - & - & $\begin{array}{c}\text { CP, DA, DP, DF, DMG, } \\
\text { MAF, OM, PI, RSA, RM, } \\
\text { RP }\end{array}$ \\
\hline Get order & - & - & - & - & - & - \\
\hline Develop product & - & - & - & - & $\mathrm{AC}$ & - \\
\hline Fulfil order & $\begin{array}{l}\text { DIG, GG, MEG, MG, PP, } \\
\text { RCUC, TESS }\end{array}$ & MUT & - & - & $\begin{array}{l}\text { BP, DSM, } \\
\text { LS, MG }\end{array}$ & $\begin{array}{c}\text { CS, CI, DSM, DIA, LS, MG, } \\
\text { NR, pMEG, PP, PSS, } \\
\text { RCUC, RSA, SG, SM }\end{array}$ \\
\hline Support product & - & - & - & - & $\mathrm{AC}$ & - \\
\hline Manage finance & - & - & - & - & - & - \\
\hline Support personnel & - & - & - & - & - & CRS \\
\hline Manage technology & GG, MG, RS & $\begin{array}{l}\text { RAT, RET, } \\
\text { RS, R\&D }\end{array}$ & $\begin{array}{l}\text { MV, OS, } \\
\text { RAT, RET, } \\
\text { RS, UL }\end{array}$ & $\begin{array}{l}\text { MO, OS, } \\
\text { RAT, RET, } \\
\quad \text { RS }\end{array}$ & MG, RS & $\begin{array}{c}\text { DA, DP, DF, MS, MG, MO, } \\
\text { PMU, PI, PSS, RAT, RET, } \\
\text { ST, SCADA, SG, SD, SE }\end{array}$ \\
\hline Corporate learning & - & - & - & - & - & $\mathrm{BD}, \mathrm{RD}, \mathrm{SE}$ \\
\hline
\end{tabular}

Assist customers (AC) [27] is with survivability features at blackouts, such as backup generators, power storages, or control components. This service is clearly associated with the end-user's part of the power grid, and it might be related to an idea for a new consultation service for the industry. It is associated with the consumer component and product development and product support business processes.

Backup power (BP) [27-29] improves resilience, mostly in a form of gas-fired generators. A backup power source is installed on the customer side and is an alternative means to order fulfilment process. It is associated with the consumer component and fulfils order business process.

Blackout drill (BD) [28] is a preparatory measure for better disaster management. Blackout drills are associated with the control component and corporate learning business process.

Contingency plan (CP) [30] is a tool such as cutting off consumers by a set of criteria to minimize economic loss. Other types of contingency plans might be deduced for grid operators and consumers. Contingency plans are likely to be related to the control component and strategy formulation and directing business processes.

Control switch (CS) [29] may improve resilience, e.g., after receiving a signal from a smart meter a control software switches to a backup power or changes typology of a grid. This tool is associated with the control component and order fulfilment business processes.

Controlled islanding (CI) [31-33] may improve resilience of a power grid. The core idea is based on splitting a grid into islands of balanced production-consumption, usually to avoid cascade failure, minimize lost load and speed-up restoration. Controlled islanding is related to the control component (though producers and consumers might be affected as well, and redesign of the grid would affect most of the physical components) and order fulfilment business processes.

Crew staging (CRS) [34] is a preparatory measure to improve resilience. Crew staging is likely to be associated with the control component and support personnel business process.

Damage assessment (DA) [27, 34-36] provides the size and extent of the damage and resources required. Damage assessment is likely to be associated with the control component and direct business and manage technology business processes.

Damage prediction $(D P)[34]$ is a preparatory measure to improve resilience. Damage prediction is likely to be associated with control component and direct business and manage technology business processes.

Demand-side management (DSM) [37] is a process of managing energy consumption. Demand-side management is related to control and consumer components and order fulfilment business process.

Disaster forecasting (DF) [30], if the industry is notified about the disaster in advance, damage might be minimized. Disaster forecasting is related to the control component and business direction and technology management business processes.

Disaster management group (DMG) [38] is used to manage the impacts of power outages. Groups in Germany are formed from local fire brigades, administrative departments, and a disaster management authority [38]. The UK has similar groups in energy [39] and other sectors. Disaster management group is a part of the control component and business directing business process.

Distributed automation (DIA) [29] enhances the resilience of distribution system via accurate and in-time control. Distributed automation is associated with the control component and order fulfilment business process. 
Distributed generation (DIG) [29] enhances the resilience of distribution system via local sources of energy. Distributed generation is associated with the producer component and order fulfilment business process.

Gas-fired generator (GG) [40] is used for distributed generation. Distributed generation is associated with the producer component and order fulfilment and technology management business processes.

Integrate black-start resources (IB) [41] may improve resilience. It is associated with the producer component and business direction business process.

Load shedding (LS) [42] is an emergency control action to avoid cascade failure by cutting a subset of customers. Load shedding is associated with control and consumer components and order fulfilment business process.

Maintenance scheduling (MS) [43-45] may improve resilience of the power grid. Maintenance is associated with the control component and technology management business process.

Manage vegetation (MV) [41] is mostly by cutting trees near overhead power lines. It is associated with the power line component and technology management business process.

Microgrid (MG) [46-52] is a group of interconnected consumers and producers of energy resources that act as a single controllable entity with respect to the grid. Microgrid may be associated with producer, consumer, control components, and order fulfilment and technology management business processes.

Mobile emergency generator (MEG) [53] is used for temporal distribution generation during emergencies. It is associated with producer component and fulfils order business process.

Mobile unit transformer (MUT) [54] is used during failures of stationary transformers or their inability to process the load. It is related to substation component and fulfils order business process.

Modelling using IEEE bus test systems (MO) [33] and many other authors have mentioned that IEEE bus models are useful for evaluating for resilience changes to power grids. IEEE bus is associated with substation and control components and technology management business process.

Mutual assistance framework (MAF) [27] has been set up in Europe to aid restoration after major power disasters with access to spare parts and workforces. The framework is associated with the control component and business direction business process.

Network reconfiguration (NR) [55-59] is as automatic and dynamic change of topology of the power grid. Network reconfiguration is likely associated with the control component and order fulfilment business process.

Optimal reactive reserve $(O R)$ [60] that meets demand spikes under heavily loaded conditions allows the avoidance of voltage instability problems. Optimal reactive reserve is likely associated with the producer component and strategy formulation business processes.

Outage management system (OM) [61] can dramatically decrease the durations and sizes of power outages. Outage management system is associated with the control component and business direction business process.

Overhead structure reinforcement (OS) [62] improves resilience of the grid, which can be achieved by use of robust materials, optimization of tower foundations for soil type and weather conditions. Overhead structure reinforcement is associated with the power line component and technology management business process.

Performance prediction of renewable-based resources (PP) [63] improves resilience of the grid by overcoming uncertainty and variability of renewable-based production of electricity. Performance prediction is associated with producer and control components and order fulfilment business process.

Phasor measurement unit (PMU) [64-68] is a device that provides synchronized, real-time, dense, and highly accurate measurement of current and voltage phasors. PMU is associated with the control component and technology management business process.

Post-incident investigation practices (PI) [35] are used to study major outages post factum and improve recovery for the future. These investigation practices are associated with the control component and business direction and technology management business process.

Power system stabilizer (PSS) [69] dynamically provides supplementary feedback signals aiding power system control, thus adding the grid's resilience. PSS is associated with the control component and order fulfilment and technology management business process.

Prepositioning of mobile emergency generators ( $p M E G$ ) [53] is a technique for optimization of location mobile emergency generators. It is associated with control component and fulfils order business process.

Real-time statistical analysis (RSA) [70] may identify signals of an approaching blackout; thus utilization of this analysis followed by blackout preventive actions aids the grid's resilience. The real-time analysis is associated with the control component and business direction and order fulfilment business process.

Reallocate transmission routes (RAT) [41, 71]: a grid with elevated or reallocated substations (and power lines) might be less prone to extreme weather and floods thus more resilient. Reallocation of substations is associated with substations and power lines components and strategy formulation and technology management business processes.

Redundant transmission routes (RED) [71]: construction of redundant transmission lines improves resilience of the power grid. Transmission routes are associated with substations and power line components and strategy formulation and technology management business processes.

Reinforce structure (RS) [41] increases resilience of the grid. It is associated with all power grid components and technology management business process.

Research and development of transformers for resilience (R\&D) [35]: continuous $R \& D$ of transformers for resilience improves resilience of the power grid. This activity is associated with the substation component and technology management business process. 
Resilience-constrained hourly unit commitment (RCUC) [72]: this technique optimizes the loading of generators. It is associated with the produces and controller components and fulfils order business process.

Restoration drills (RD) [35] increase resilience of the power grid. Restoration drills are associated with the control component and corporate learning business process.

Restoration management (RM) [34,73] may be used to increase resilience of the power grid. It is likely to be associated with the control component and business direction business process.

Restoration priority $(R P)$ [74] may reduce loss load thus improving resilience of the power grid. Restoration priority is likely to be associated with the control component and business direction business process.

Satellite technology (ST) [75] may be used to detect power outages in real time, thus improving resilience of the power grids. It is associated with the control component and technology management business process.

Supervisory control and data acquisition (SCADA) [6, $76,77]$ is a data collection tool for control and management of the grid. SCADA is associated with the control component and technology management business process.

Smart grid (SG) $[10,65,78-84]$ is a more resilient version of the power grid. A smart grid utilizes advanced data collection and analysis. It is associated with the control component (yet have physical and virtual sensors in all other components) and order fulfilment and technology management business processes.

Smart meter $(S M)[10,40,55,61,84]$ is a device that feeds data for dynamic control of the grid (e.g., production, load). Smart meters are installed to all components of the grid but are associated with the control component and order fulfilment business process.

Standards' development (SD) [35] for utility cyber control systems is a strategy for increasing resilience of the grid; this can be generalized to development of power grid standards for resilience. Standards' development is associated with the control component and technology management and corporate learning business processes.

State estimation (SE) $[68,77]$ provides a real-time state of the power system, which is relevant for reactive and proactive control of the power grid. State estimation is associated with the control component and technology management business process.

Transportable energy storage system (TESS) [85] is proposed for post-disaster restoration of large distribution grids via initialization of microgrids and consists of an energy storage, means of transportation, control of transportation, and application scheme.

Undergrounding power lines (UL) $[41,71]$ could enhance the resilience via replacement of overhead power as the underground power lines are less prone to wind-induced damage, lightning, and vegetation contact. The price of higher installation and repair costs could be offset against cost of damage or interruption to service. Undergrounding is associated with the power line component and technology management business process.

\section{Discussion}

4.1. Simulation Modelling. Volume- and time-driven resilience assessment frameworks do not provide insights into points of failure, triggers, probabilities of failures or triggers, and asset conditions. These are highly relevant information to link both hazards and tools to power grid components. They are needed for resilience research and if a resilience assessment framework does not address these factors, then it has limited application. However, resilience assessment frameworks that do address these factors are subsector specific and, moreover, asset-specific and therefore have an absence of a systemic and cross-sectoral understanding of resilience. They would also require interdependency studies and cross-sectors resilience-driven projects.

The need for generic and the need for specific resilience assessment frameworks are a contradiction. This contradiction can be removed by the abstraction between two stages of resilience calculation. The system output is calculated at the sector- or asset-specific first stage by the means of real system or a simulation model. These sector-specific outputs are processed by the same function into a generic resilience values at the second stage.

Resilience is an emergent quality of a system to a hazard. Due to the constructional and behavioral complexity of the system of interest, the power grids, this emergent quality cannot be predicted without a system. A hazard and its impact on the power grid from the producers to the consumers increase complexity of the resilience research, while the number of potential tools for resilience engineering and the number of their combinations makes it a challenging research domain.

It is impossible to replicate most of hazards in a real power grid, and for many threats, testing is highly expensive to emulate even on a highly limited scale if legal, e.g., a cyberterrorism or electromagnetic interference, which makes physical experimentation as a method for resilience research a very limited application. Mental experimentation has limited use for a conceptual study of resilience which attempts to quantify the improvement from alternative interventions and is an unreasonable method for resilience engineering of complex systems using a toolbox. Post-event studies of major outages may provide some important information and insights, and the lack of observational capabilities on site during an emergency can be overcome with multitude of sensors logging power grid supply and consumption; however, access to this data is usually limited due to organizational reasons; it is a unique case that cannot be replicated, and it is ex-post evaluation limiting its usability for resilience engineering. Inductive reasoning is partially applicable to resilience research as it relies on a strong and cogent selection of facts, which is limited for the reasons above, similarly, with formalization for the follow-up logical and mathematical reasoning. Theoretical reasoning would be a method of predicting results, but the theory for engineering resilience does not exist; therefore, it is an inapplicable method at this moment. A model may selectively address the constructional and behavioral complexity of a system and provide insights into the resilience value of alternative subsets of tools without 
the costs or barriers of real-world experimentation which makes modelling and especially computational modelling, the most suitable method for ex-post and ex-ante resilience research.

Banks et al. [86] classify simulation models as either static or dynamic, deterministic, stochastic, discrete, or continuous. A model for resilience research and engineering must be dynamic since static models have very limited capabilities in addressing behavioral aspects; stochastic as complex multidomain deterministic rules are very challenging to define; discrete because continuous models are mostly based on differential and integral calculus that if applicable has highly specialized application, e.g., for thermodynamics. Dynamic stochastic discrete models appear most suitable; however, multiple formalisms for simulation modelling fit these characteristics, and multiple formalisms might be used within a complex computational model with some submodels being static, deterministic, or continuous.

Some architectural considerations could be made for the modelling- and toolbox-driven resilience research. It can be safely assumed that resilience research would incorporate massive simulation modelling. A colossal number of interactions between elements are expected. A state or a change of state of elements before an element may result a change of state in this element. A high-level and lightweight computation is a preferred option unless required otherwise. It is beneficial to represent a power grid as a network of assets producing, transforming, redirecting, or consuming electric energy, because it fits the typology of assets and is efficiently computable within vector, matrix, or tensor algebras and is applicable and partially transferrable to modelling of infrastructures from other sectors that is especially relevant for multisectoral resilience research.

Interfaces for control and information exchange model and submodel are critical, as is parallelization of modelling and computation to improve computational durations. A hazard may affect the behavior of consumers, which is one of viable research objectives, and it is commonly addressed with agent-based modelling. Toolbox-induced changes in a model assume the same domain language to describe assets within the model and tools from the toolbox, and ontology can address both the structure of the language and the database of assets and tools.

According to Kelly et al. [87], five modelling approaches are most commonly used for integrated environmental assessment and management. Each of these approaches has been used for modelling complex systems: system dynamics [88, 89], Bayesian networks [90, 91], coupled component models [92], agent-based models [93, 94], and knowledgebased models [95]. In additional to the summary of these approaches (see Tables 1 and 3 in [87]), Kelly et al. [87] provided a heuristic for selection of one of these approaches under standard application (see Figure 1 in [87]). However, as is shown in review papers [96-107] a more comprehensive heuristics on a larger spectrum of modelling approaches would benefit the resilience research and engineering.

4.2. Toolbox. The toolbox is a collection and description of tools to improve resilience of a power grid. A grid has a certain level of resilience to a hazard, and by changing the tools available to the grid its resilience may stay the same, and it may be increased or decreased to the same hazard. A change is based on intervention of a subset of tools into the grid, and tools within a subset might be utilized with a different intensity. Simulation modelling is the most convenient method to evaluate the resilience of a changed grid.

Power grid components and organizational business processes are used to structure the toolbox, which currently may be associated with a two-dimensional array, as a subset for a change. A network-based model of a grid may also be represented with arrays. Therefore, this approach on a theoretical level allows utilization of one of the most convenient and efficient methods for mass computation, vector operations. Vector, matrix, and tensor algebras provide a mathematical apparatus for this and more complex computations, e.g., incorporating dynamics or multilayered virtual subgrids; combinatorics and set theory could support scenario design.

Qualitative resilience assessment frameworks [19] which could be used to direct attention to certain 'cells' in the toolbox for these frameworks are based on best practices for resilience.

Examples of such frameworks are a semiquantitative approach proposed by Shirali et al. [108] qualitative frameworks that could be transformed into a semiquantitative index and subsets of resilience indicators proposed by van der Merwe et al. [109].

The toolbox shows the areas currently lacking tools to improve resilience. While this could be partially explained by insufficiently full and systematic literature review, this also indicated the lack of interest in this area, and if the lack of interest is unreasonable, then the toolbox shows gaps in the current state of resilience research and engineering.

While the current two-dimensional classification provides a valuable categorization for the tools to improve resilience, it might be insufficient because it does not address the constructional complexity of a power grid and its components. The component dimension might be replaced or extended with system's representation (see Figure 2.3 in [110]), systems engineering processes (see Figure 1.1 in [110]), domain ontology [111], or systems holarchy [112], though the latter is more suitable for grid modelling, but a strong relationship between the holarchy and the toolbox must be established beforehand. Other classifications might be used as well.

Similar toolboxes could be created for resilience research and engineering of other sectors of infrastructure. Multisectoral toolboxes would require an additional research, probably resulting in a higher-dimensionality of classification matrices and generic functional-constructional descriptors of tools.

4.3. Resilience Value. Most of the general quantitative resilience assessment frameworks in $[19,20]$ utilize volume, time, or volume-over-time data to calculate resilience value. These variables and different operators from different branches of mathematics form alternative mathematical equations for calculation of resilience value. Each equation is supported by 
TABLE 5: A temporal outlook to disruptive events [8]. Relative to a disruptive event, resilience may be improved long before, before, during, after, and long after the event.

\begin{tabular}{|c|c|c|c|c|}
\hline Time period & Objectives & System state & System function & Event feature \\
\hline Long before & $\begin{array}{c}\text { Identify possible events, know } \\
\text { system weaknesses, plan response } \\
\text { and restoration, prepare resources }\end{array}$ & Normal & $\begin{array}{l}\text { Awareness, } \\
\text { planning, and } \\
\text { preparation }\end{array}$ & Predisposition \\
\hline Before & $\begin{array}{l}\text { Monitor system, monitor threats, } \\
\text { ensure resources are available, } \\
\text { switch to alert state if a threat is } \\
\text { detected }\end{array}$ & Alert & $\begin{array}{l}\text { Monitor, detect, } \\
\text { recognition }\end{array}$ & Precursors \\
\hline During & $\begin{array}{l}\text { Stop effect propagation, core goals, } \\
\text { manage cascade failures }\end{array}$ & Emergency & $\begin{array}{l}\text { Containment, } \\
\text { mitigation }\end{array}$ & Effects \\
\hline After & $\begin{array}{c}\text { Resume normal operations, reverse } \\
\text { alert/emergency, manage delayed } \\
\text { failures }\end{array}$ & Restoration & $\begin{array}{l}\text { Repair, } \\
\text { reconfigure, } \\
\text { replacement }\end{array}$ & Impact \\
\hline Long after & $\begin{array}{c}\text { Understand what happened, know } \\
\text { why it happened, plan and } \\
\text { implement actions to improve } \\
\text { resilience }\end{array}$ & Recovery & $\begin{array}{l}\text { Reflection, } \\
\text { learning, } \\
\text { improvement }\end{array}$ & Outcome \\
\hline
\end{tabular}

at least one line of argumentation which could be probed and developed further. Other ideas may and would likely result from other equations, for example,

(1) Minimum resilience value is taken as the resilience of the system, and the volume might now be the lowest delivery. Resilience value is calculated for each time value at the first step, and the minimum resilience value is selected at the second step.

(2) Lowest (minimum) delivery volume defines the resilience of the system. The minimum value is selected for the equation with the associated time and this time is used to select the baseline value.

(3) This equation can be further extended by incorporating more statistical values:

(a) mean (the average) of delivered and baseline volume during at disrupted state,

(b) median (the middle value of an ordered list) of volume,

(c) mode (the most common value),

(d) filtering out outliers with the calculation of averages (or minimum, as above),

(e) using other statistical measures and statistical analysis techniques, e.g., quartiles with the associated box-and-whisker plots.

(4) Statistics may provide additional insights. For example, skewness may indicate whether the system fails or recovers faster, while kurtosis may indicate whether the system has extreme drops of performance or how fast the hardest part of the system is processed. While these can be easily deduced from the visualization, the quantitative statistical technique is instrumental for automatic optimization of the infrastructure.

An equation can be used on natural (e.g., litres) and normalized (e.g., percent) data. Some considerations might require nonlinear normalization (e.g., onto a logarithmic scale for similar reasons the Richter magnitude scale is a logarithmic scale) of the input data or resilience values, in this case an equation might undergo adjustments. The nonlinear normalization might be the answer to the intensity aspect of the hazards' profile, but this requires additional research.

The significance of each tool in isolation with respect to resilience improvement is questionable unless a sound logical and pragmatic reasoning is provided; usually, papers are lacking in that aspect. In the event the toolbox is applied for resilience research, then one or more equations would be selected, combined, and developed. Simulation modelling would support any tool and related equations, subject to limitations of the platform.

4.4. Decision-Making. Several preconditions must be met before application of a resilience assessment framework as resilience values are calculated for strategic decision-making and operationalization of the decisions. If resilience value is insufficient, then a change might be introduced into the system resulting in a new resilience value of the changed system. The difference between the old and new resilience values represents the impact of the change on resilience, and the delta resilience might be compared to delta sustainability or monetary investment.

Overall, resilience engineering is likely a continuous activity and resilience of a complex system can be addressed at different stages to disruptive events; see Table 5.

Multiple methods can be used to define the criteria to consider whether the output of each resilience assessment framework indicates a 'good' level of resilience. If resilience value is used for decision-making, it is multicriteria decisionmaking, and thus this task is about naming complementary criteria for the multicriteria decision-making. Three approaches to multicriteria decision-making are listed below from the least to the most comprehensive. 
Single criteria indicators: with resilience value as supply/demand ratio, the criteria are the threshold value for the volume of delivery or capacity margin.

Multicriteria n-lemmas: an example of such concept is a well-known cost-quality-time triangle with a heuristics rule that for any system it is possible to meet two qualities only. Similar triangle is associated with the resilience of electricity system [113] presenting sustainability-security of supply-affordability triangle, where resilience is a part of security and decarbonization is a part of sustainability indicators.

Evaluation frameworks: HM treasury provides guidance on how to appraise and evaluate policies, projects, and programmes; see The Green Book [114].

\section{Conclusions}

A structured collection of tools for engineering resilience and an approach for resilience research to improve the resilience of a power grid infrastructure is described in this paper. The collection is a two-dimensional array formed from a classification of components of a power grid and a typology of business processes. These two dimensions provide a physical and operational outlook for a power grid. The approach for resilience research is based on building a simulation model for a power grid which utilizes a resilience assessment equation to assess its baseline resilience to a hazards profile, then iteratively selecting a subset of tools from the collection and introducing these as interventions in the power grid simulation. Calculating the difference in resilience associated with each subset supports multicriteria decision-making to find the most convenient subset of interventions for a power grid and hazards profile.

This highlights the importance of a portfolio which is strategies which should take account of variety of natural disasters relevant to the regions/geographical areas of the power grid (in addition to general hazards), as well as compensating for design decisions which can compromise resilience.

The approach outlined of iterative testing of subsets of tools assumes simulation modelling. The simulation model should be in-line with the structured description of the elements of the collection and the possible paths of impact of hazards. Hazard is a mandatory element of resilience experience; however, resilience of a system to a hazard is less relevant then resilience of a system to a hazards' profile. Matrix algebra, set theory, and combinatorics allow automatic construction of scenarios within this approach. Volume, time, or volume-over-time resilience assessment framework could be selected or designed for the simulation modelling architecture. The resulting resilience value, in combination with other factors, could be used for multicriteria decisionmaking on the quality of the subset.

Resilience is an emergent quality of a power grid system, and therefore resilience research and interventions must be system-driven. Usually, multiple infrastructures are utilized by social or production systems, and a hazard often affects multiple infrastructures as well-illustrated by assessment of volcanic hazards by Wilson et al. [115], which also states the importance of hazards' profile for a country. Moreover, interdependencies $[1,2]$ between infrastructures may impact the recovery and resilience of a single infrastructure. Therefore, simulation-based search/optimization for a resilient infrastructure would benefit from a simultaneous search/optimization for multisectoral resilience; e.g., Najafi et al. [52] described resilience improvement of power-water distribution system. However, simulation-based resilience research and engineering require in-depth single- or multitopic analysis of hazards, infrastructure components, vulnerabilities, tools, regions, simulation modelling techniques, and search or optimization algorithms for the follow-up model driven resilience research and engineering.

\section{Data Availability}

Published articles provide the data used to support the findings of this study. The selection rules for these articles are included within the article.

\section{Conflicts of Interest}

The manuscript has no conflicts of interest with the source of funding or otherwise.

\section{Acknowledgments}

We kindly acknowledge EPSRC grant funding reference EP/N010019/1 regarding the ENCORE project on engineering complexity resilience.

\section{References}

[1] J. W. Hall, J. J. Henriques, A. J. Hickford, and R. J. Nicholls, "Systems-of-systems analysis of national infrastructure," Proceedings of the Institution of Civil Engineers: Engineering Sustainability, vol. 166, no. 5, pp. 249-257, 2013.

[2] M. A. Ehlen and V. N. Vargas, "Multi-hazard, multi-infrastructure, economic scenario analysis," Environment Systems \& Decisions, vol. 33, no. 1, pp. 60-75, 2013.

[3] Z. Bo, O. Shaojie, Z. Jianhua, S. Hui, W. Geng, and Z. Ming, "An analysis of previous blackouts in the world: lessons for China's power industry," Renewable and Sustainable Energy Reviews, vol. 42, pp. 1151-1163, 2015.

[4] "Billion-Dollar Weather and Climate Disasters: Table of Events, National Oceanic and Atmospheric Administration, 2019," https://www.ncdc.noaa.gov/billions/events/US/1980-2019.

[5] S. N. Talukdar, J. Apt, M. Ilic, L. B. Lave, and M. G. Morgan, "Cascading failures: Survival versus prevention," The Electricity Journal, vol. 16, no. 9, pp. 25-31, 2003.

[6] P. Andriani and B. McKelvey, "Beyond Gaussian averages: Redirecting international business and management research toward extreme events and power laws," Journal of International Business Studies, vol. 38, no. 7, pp. 1212-1230, 2007.

[7] D. F. Warne, Newnes Electrical Power Engineer's Handbook, Elsevier, Oxford, UK, 2nd edition, 2005.

[8] M. Mayfield, G. Punzo, R. Beasley, G. Clarke, N. Holt, and S. Jobbins, "Challenges of complexity and resilience in complex engineering systems," ENCORE Network+ White Paper, 2018. 
[9] S. Mukherjee, R. Nateghi, and M. Hastak, "A multi-hazard approach to assess severe weather-induced major power outage risks in the U.S.," Reliability Engineering \& System Safety, vol. 175, pp. 283-305, 2018.

[10] Z. Bie, Y. Lin, G. Li, and F. Li, "Battling the extreme: a study on the power system resilience," Proceedings of the IEEE, vol. 105, no. 7, pp. 1253-1266, 2017.

[11] “"National Risk Register of Civil Emergencies - 2017 Edition," Cabinet Office, National security and intelligence, and The Right Honorable Caroline Nokes MP," https://www.gov.uk/ government/publications/national-risk-register-of-civil-emergencies-2017-edition, 2017.

[12] A. Collins, “The Global Risks Report 2018," Tech. Rep., World Economic Forum, Geneva, Switzerland, 2018.

[13] "Black Sky Hazards, EIS Council," https://www.eiscouncil .org/blackSky.aspx, 2019.

[14] T. Huang, S. L. Voronca, A. A. Purcarea, A. Estebsari, and E. Bompard, "Analysis of chain of events in major historic power outages," Advances in Electrical and Computer Engineering, vol. 14, no. 3, pp. 63-70, 2014.

[15] L. Fisher, "More than 70 ways to show resilience," Nature, vol. 518, p. 35, 2015.

[16] "Presidential Policy Directive - Critical Infrastructure Security and Resilience," The White House, 2013, https://obamawhitehouse.archives.gov/the-press-office/2013/02/12/presidentialpolicy-directive-critical-infrastructure-security-and-resil.

[17] "Keeping the country running: natural hazards and infrastructure, Cabinet Office," 21 October 2011, https://www.gov.uk/government/publications/keeping-the-country-running-naturalhazards-and-infrastructure.

[18] UNISDR, 2009 UNISDR Terminology for Disaster Risk Reduction, 2009, https://www.unisdr.org/we/inform/publications/ 7817.

[19] S. Hosseini, K. Barker, and J. E. Ramirez-Marquez, "A review of definitions and measures of system resilience," Reliability Engineering \& System Safety, vol. 145, pp. 47-61, 2016.

[20] N. Yodo and P. Wang, "Engineering resilience quantification and system design implications: A literature survey," Journal of Mechanical Design, vol. 138, no. 11, Article ID 111408, 2016.

[21] M. Omer, A. Mostashari, and R. Nilchiani, "Assessing resilience in a regional road-based transportation network," International Journal of Industrial and Systems Engineering, vol. 13, no. 4, pp. 389-408, 2013.

[22] B. M. Ayyub, "Systems resilience for multihazard environments: Definition, metrics, and valuation for decision making," Risk Analysis, vol. 34, no. 2, pp. 340-355, 2014.

[23] D. Gama Dessavre, J. E. Ramirez-Marquez, and K. Barker, "Multidimensional approach to complex system resilience analysis," Reliability Engineering \& System Safety, vol. 149, pp. 34-43, 2016.

[24] U. S. Bititci, K. Mendibil, V. Martinez, and P. Albores, "Measuring and managing performance in extended enterprises," International Journal of Operations and Production Management, vol. 25, no. 4, pp. 333-353, 2005.

[25] U. S. Bititci, V. Martinez, P. Albores, and K. Mendibil, "Creating and sustaining competitive advantage in collaborative systems: The what and the how," Production Planning and Control, vol. 14, no. 5, pp. 410-424, 2003.

[26] S. Oktaufanus, "Improvement CIMOSA," http://shutsatria .blogspot.com/2012/01/v-behaviorurldefaultvml-o.html, 2012.

[27] C. Chen, J. Wang, and D. Ton, "Modernizing distribution system restoration to achieve grid resiliency against extreme weather events: an integrated solution," Proceedings of the IEEE, vol. 105, no. 7, pp. 1267-1288, 2017.

[28] S. B. Miles, H. Gallagher, and C. J. Huxford, "Restoration and impacts from the september 8, 2011, san diego power outage," Journal of Infrastructure Systems, vol. 20, no. 2, Article ID 05014002, 2014.

[29] J. Najafi, A. Peiravi, and J. M. Guerrero, "Power distribution system improvement planning under hurricanes based on a new resilience index," Sustainable Cities and Society, vol. 39, pp. 592604, 2018.

[30] K. Kim and Y. Cho, "Estimation of power outage costs in the industrial sector of South Korea," Energy Policy, vol. 101, pp. 236-245, 2017.

[31] M. Panteli, D. N. Trakas, P. Mancarella, and N. D. Hatziargyriou, "Boosting the power grid resilience to extreme weather events using defensive islanding," IEEE Transactions on Smart Grid, vol. 7, no. 6, pp. 2913-2922, 2016.

[32] S. Kamali and T. Amraee, "Blackout prediction in interconnected electric energy systems considering generation redispatch and energy curtailment," Applied Energy, vol. 187, pp. 50-61, 2017.

[33] V. Thirugnanasambandam and T. Jain, "Placement of synchronized measurements for power system observability during cascaded outages," International Journal of Emerging Electric Power Systems, vol. 18, no. 6, 2017.

[34] R. Nateghi, S. D. Guikema, and S. M. Quiring, "Forecasting hurricane-induced power outage durations," Natural Hazards, vol. 74, no. 3, pp. 1795-1811, 2014.

[35] B. A. Wender, M. G. Morgan, and K. J. Holmes, "Enhancing the resilience of electricity systems," Engineering Journal, vol. 3, no. 5, pp. 580-582, 2017.

[36] K. Forssén, K. Mäki, M. Räikkönen, and R. Molarius, "Resilience of electricity distribution networks against extreme weather conditions," ASCE-ASME Journal of Risk and Uncertainty in Engineering Systems, Part B: Mechanical Engineering, vol. 3, no. 2, Article ID 021005, 2017.

[37] H. Syadli, M. P. Abdullah, M. Y. Hassan, and F. Hussin, "Demand side management for reducing rolling blackouts due to power supply deficit in sumatra," Jurnal Teknologi, vol. 69, no. 5, pp. 39-43, 2014.

[38] T. Münzberg, M. Wiens, and F. Schultmann, "A spatial-temporal vulnerability assessment to support the building of community resilience against power outage impacts," Technological Forecasting \& Social Change, vol. 121, pp. 99-118, 2017.

[39] Department for Business, Energy, and Industrial Strategy, "Electricity Supply Emergency Code, Department for Business, Energy \& Industrial Strategy," https://www.gov.uk/government/publications/electricity-supply-emergency-code, 2018.

[40] S. Baik, A. L. Davis, and M. G. Morgan, "Assessing the cost of large-scale power outages to residential customers," Risk Analysis, vol. 38, no. 2, pp. 283-296, 2018.

[41] S. Ma, B. Chen, and Z. Wang, "Resilience enhancement strategy for distribution systems under extreme weather events," IEEE Transactions on Smart Grid, vol. 9, no. 2, pp. 1442-1451, 2018.

[42] R. Mageshvaran and T. Jayabarathi, "GSO based optimization of steady state load shedding in power systems to mitigate blackout during generation contingencies," Ain Shams Engineering Journal, vol. 6, no. 1, pp. 145-160, 2014.

[43] M. Abirami, S. Ganesan, S. Subramanian, and R. Anandhakumar, "Source and transmission line maintenance outage scheduling in a power system using teaching learning based 
optimization algorithm," Applied Soft Computing, vol. 21, pp. 72-83, 2014.

[44] S. Tang, C. Hale, and H. Thaker, "Reliability modeling of power transformers with maintenance outage," Systems Science \& Control Engineering, vol. 2, no. 1, pp. 316-324, 2014.

[45] G. Ji, W. Wu, and B. Zhang, "Robust generation maintenance scheduling considering wind power and forced outages," IET Renewable Power Generation, vol. 10, no. 5, pp. 634-641, 2016.

[46] C. Stefanovic, M. Angjelichinoski, P. Danzi, and P. Popovski, "Resilient and secure low-rate connectivity for smart energy applications through power talk in DC microgrids," IEEE Communications Magazine, vol. 55, no. 10, pp. 83-89, 2017.

[47] X. Liu, M. Shahidehpour, Z. Li, X. Liu, Y. Cao, and Z. Bie, "Microgrids for enhancing the power grid resilience in extreme conditions," IEEE Transactions on Smart Grid, vol. 8, no. 2, pp. 589-597, 2017.

[48] H. Farzin, M. Fotuhi-Firuzabad, and M. Moeini-Aghtaie, "Enhancing power system resilience through hierarchical outage management in multi-microgrids," IEEE Transactions on Smart Grid, vol. 7, no. 6, pp. 2869-2879, 2016.

[49] S. Bird and C. Hotaling, "Multi-stakeholder microgrids for resilience and sustainability," Environmental Hazards, vol. 16, no. 2, pp. 116-132, 2017.

[50] Y. Koraz and A. Gabbar, "Risk analysis and self-healing approach for resilient interconnect micro energy grids," Sustainable Cities and Society, vol. 32, pp. 638-653, 2017.

[51] K. B. Jones, M. James, and R.-A. Mastor, "Securing our energy future: three international perspectives on microgrids and distributed renewables as a path toward resilient communities," Environmental Hazards, vol. 16, no. 2, pp. 99-115, 2017.

[52] J. Najafi, A. Peiravi, A. Anvari-Moghaddam, and J. M. Guerrero, "Resilience improvement planning of power-water distribution systems with multiple microgrids against hurricanes using clean strategies," Journal of Cleaner Production, vol. 223, pp. 109-126, 2019.

[53] S. Lei, J. Wang, C. Chen, and Y. Hou, "Mobile emergency generator pre-positioning and real-time allocation for resilient response to natural disasters," IEEE Transactions on Smart Grid, vol. 9, no. 3, pp. 2030-2041, 2018.

[54] G. A. Hamoud, "Use of mobile unit transformers in high voltage load stations," in Proceedings of the 10th International Conference on Probablistic Methods Applied to Power Systems, Rincon, Ga, USA, 2008.

[55] S. Baik, M. G. Morgan, and A. L. Davis, "Providing limited local electric service during a major grid outage: a first assessment based on customer willingness to pay," Risk Analysis, vol. 38, no. 2, pp. 272-282, 2018.

[56] J. Wei and D. Kundur, "GOAliE: goal-seeking obstacle and collision evasion for resilient multicast routing in smart grid," IEEE Transactions on Smart Grid, vol. 7, no. 2, pp. 567-579, 2016.

[57] Y. Fang and G. Sansavini, "Optimizing power system investments and resilience against attacks," Reliability Engineering \& System Safety, vol. 159, pp. 161-173, 2017.

[58] H. Lin, C. Chen, J. Wang et al., "Self-healing attack-resilient PMU network for power system operation," IEEE Transactions on Smart Grid, vol. 9, no. 3, pp. 1551-1565, 2018.

[59] A. Nuhanović, J. Hivziefendić, and A. Hadžimehmedović, "Distribution network reconfiguration considering power losses and outages costs using genetic algorithm," Journal of Electrical Engineering, vol. 64, no. 5, pp. 265-271, 2013.
[60] S. Padaiyatchi and M. Daniel, "OPF-based reactive power planning and voltage stability limit improvement under single line outage contingency condition through evolutionary algorithms," Turkish Journal of Electrical Engineering and Computer Sciences, vol. 21, no. 4, pp. 1092-1106, 2013.

[61] H. Sun, Z. Wang, J. Wang, Z. Huang, N. Carrington, and J. Liao, "Data-driven power outage detection by social sensors," IEEE Transactions on Smart Grid, vol. 7, no. 5, pp. 2516-2524, 2016.

[62] D. Kyung, Y. Choi, S. Jeong, and J. Lee, "Improved performance of electrical transmission tower structure using connected foundation in soft ground," Energies, vol. 8, no. 6, pp. 49634982, 2015.

[63] D. Apostolopoulou, Z. De Grève, and M. McCulloch, "Robust optimization for hydroelectric system operation under uncertainty," IEEE Transactions on Power Systems, vol. 33, no. 3, pp. 3337-3348, 2018.

[64] J.-C. Chen, W.-T. Li, C.-K. Wen, J.-H. Teng, and P. Ting, "Efficient identification method for power line outages in the smart power grid," IEEE Transactions on Power Systems, vol. 29, no. 4, pp. 1788-1800, 2014.

[65] A. Ahmed, M. Awais, M. Naeem et al., "Multiple power line outage detection in smart grids: probabilistic bayesian approach," IEEE Access, vol. 6, pp. 10650-10661, 2018.

[66] A. Arabali, M. Majidi, M. S. Fadali, and M. Etezadi-Amoli, "Line outage identification-based state estimation in a power system with multiple line outages," Electric Power Systems Research, vol. 133, pp. 79-86, 2016.

[67] O. Gomez, M. A. Rios, and G. Anders, "Reliability-based phasor measurement unit placement in power systems considering transmission line outages and channel limits," IET Generation, Transmission \& Distribution, vol. 8, no. 1, pp. 121-130, 2014.

[68] X. Tai, D. Marelli, E. Rohr, and M. Fu, "Optimal PMU placement for power system state estimation with random component outages," International Journal of Electrical Power \& Energy Systems, vol. 51, pp. 35-42, 2013.

[69] M. Soliman, "Robust non-fragile power system stabilizer," International Journal of Electrical Power \& Energy Systems, vol. 64, pp. 626-634, 2015.

[70] M. Moazzami, R.-A. Hooshmand, A. Khodabakhshian, and M. Yazdanpanah, "Blackout prevention in power system using flexible AC transmission system devices and combined corrective actions," Electric Power Components and Systems, vol. 41, no. 15, pp. 1433-1455, 2013.

[71] M. Panteli and P. Mancarella, "Modeling and evaluating the resilience of critical electrical power infrastructure to extreme weather events," IEEE Systems Journal, vol. 11, no. 3, pp. 17331742, 2017.

[72] Y. Wang, L. Huang, M. Shahidehpour, L. L. Lai, H. Yuan, and F. Y. Xu, "Resilience-Constrained hourly unit commitment in electricity grids," IEEE Transactions on Power Systems, vol. 33, no. 5, pp. 5604-5614, 2018.

[73] M. Figueroa-Candia, F. A. Felder, and D. W. Coit, "Resiliencybased optimization of restoration policies for electric power distribution systems," Electric Power Systems Research, vol. 161, pp. 188-198, 2018.

[74] R. S. Liévanos and C. Horne, "Unequal resilience: The duration of electricity outages," Energy Policy, vol. 108, pp. 201-211, 2017.

[75] T. A. Cole, D. W. Wanik, A. L. Molthan, M. O. Román, and R. E. Griffin, "Synergistic use of nighttime satellite data, electric utility infrastructure, and ambient population to improve power outage detections in urban areas," Remote Sensing, vol. 9, no. 3, p. 286, 2017. 
[76] C. Yang, Z.-H. Guan, Z.-W. Liu, J. Chen, M. Chi, and G.-L. Zheng, "Wide-area multiple line-outages detection in power complex networks," International Journal of Electrical Power \& Energy Systems, vol. 79, pp. 132-141, 2016.

[77] A. Ashok, M. Govindarasu, and J. Wang, "Cyber-physical attack-resilient wide-area monitoring, protection, and control for the power grid," Proceedings of the IEEE, vol. 105, no. 7, pp. 1389-1407, 2017.

[78] C. Chen, J. Wang, F. Qiu, and D. Zhao, "Resilient distribution system by microgrids formation after natural disasters," IEEE Transactions on Smart Grid, vol. 7, no. 2, pp. 958-966, 2016.

[79] A. Dabrowski, J. Ullrich, and E. R. Weippl, "Botnets causing blackouts: how coordinated load attacks can destabilize the power grid," Elektrotechnik und Informationstechnik, vol. 135, no. 3, pp. 250-255, 2018.

[80] L. Zhao and W.-Z. Song, "Distributed power-line outage detection based on wide area measurement system," Sensors, vol. 14, no. 7, pp. 13114-13133, 2014.

[81] M. M. Othman, N. A. Salim, and I. Musirin, "Sustainability from the occurrence of critical dynamic power system blackout determined by using the stochastic event tree technique," Sustainability, vol. 9, no. 6, p. 941, 2017.

[82] A. AlMajali, A. Viswanathan, and C. Neuman, "Resilience evaluation of demand response as spinning reserve under cyber-physical threats," Electronics, vol. 6, no. 1, p. 2, 2017.

[83] E. D. Dongmo, P. Colet, and P. Woafo, "Power grid enhanced resilience using proportional and derivative control with delayed feedback," The European Physical Journal B, vol. 90, no. 1, p. 6, 2017.

[84] D. Tan, D. Baxter, S. Foroozan, and S. Crane, "A first resilient DC-dominated microgrid for mission-critical space applications," IEEE Journal of Emerging and Selected Topics in Power Electronics, vol. 4, no. 4, pp. 1147-1157, 2016.

[85] S. Yao, P. Wang, and T. Zhao, "Transportable energy storage for more resilient distribution systems with multiple microgrids," IEEE Transactions on Smart Grid, vol. 10, no. 3, 2018.

[86] J. Banks, J. S. Carson II, B. L. Nelson, and D. M. Nicol, "Introduction to simulation," in Discrete-Event System Simulation, pp. 1-22, Pearson Education Limited, Harlow, UK, 5th edition, 2014.

[87] R. A. Kelly, A. J. Jakeman, O. Barreteau et al., "Selecting among five common modelling approaches for integrated envornmental assessment and management," Environmental Modeling and Software, vol. 47, pp. 159-181, 2013.

[88] C. K. Gotangco, J. See, J. P. Dalupang et al., "Quantifying resilience to flooding among households and local government units using system dynamics: a case study in Metro Manila," Journal of Flood Risk Management, vol. 9, no. 3, pp. 196-207, 2016.

[89] Y. X. He, J. Jiao, R. J. Chen, and H. Shu, "The optimization of Chinese power grid investment based on transmission and distribution tariff policy: A system dynamics approach," Energy Policy, vol. 113, pp. 112-122, 2018.

[90] S. Hosseini and K. Barker, "Modeling infrastructure resilience using Bayesian networks: A case study of inland waterway ports," Computers \& Industrial Engineering, vol. 93, pp. 252-266, 2016.

[91] S. Hosseini, A. Al Khaled, and M. D. Sarder, "A general framework for assessing system resilience using Bayesian networks: A case study of sulfuric acid manufacturer," Journal of Manufacturing Systems, vol. 41, pp. 211-227, 2016.
[92] S. Peña-Alzate and J. E. C. Barriga, "Approaching the concepts of ecosystems resilience and stability through spatiotemporal system dynamics and agent-based modelling," Revista Facultad de Ingeniería Universidad de Antioquia, vol. 84, pp. 84-96, 2017.

[93] J. M. Gonzalez de Durana, O. Barambones, E. Kremers, and L. Varga, "Agent based modeling of energy networks," Energy Conversion and Management, vol. 82, pp. 308-319, 2014.

[94] G. Pumpuni-Lenss, T. Blackburn, and A. Garstenauer, "Resilience in complex systems: an agent- based Approach," Systems Engineering, vol. 20, no. 2, pp. 158-172, 2017.

[95] A. John, Z. Yang, R. Riahi, and J. Wang, "Application of a collaborative modelling and strategic fuzzy decision support system for selecting appropriate resilience strategies for seaport operations," Journal of Traffic and Transportation Engineering (English Edition), vol. 1, no. 3, pp. 159-179, 2014.

[96] R. W. Scholz, J. Gallati, Q. B. Le, and R. Seidl, "Integrated systems modeling of complex human-environment systems," in Environmental Literacy in Science and Society: from Knowledge to Decisions, pp. 341-372, Cambridge University Press, New York, NY, USA, 2011.

[97] A. S. R. Subramanian and T. A. A. A. I. Gundersen, "Modeling and simulation of energy systems: a review," Processes, vol. 6, no. 12, p. 238, 2018.

[98] R. H. E. M. Koppelaar, J. Keirstead, N. Shah, and J. Woods, "A review of policy analysis purpose and capabilities of electricity system models," Renewable \& Sustainable Energy Reviews, vol. 59, pp. 1531-1544, 2016.

[99] L. Shi, Q. Dai, and Y. Ni, "Cyber-physical interactions in power systems: A review of models, methods, and applications," Electric Power Systems Research, vol. 163, pp. 396-412, 2018.

[100] P. Lopion, P. Markewitz, M. Robinius, and D. Stolten, "A review of current challenges and trends in energy systems modeling," Renewable \& Sustainable Energy Reviews, vol. 96, pp. 156-166, 2018.

[101] W. L. Theo, J. S. Lim, W. S. Ho, H. Hashim, and C. T. Lee, "Review of distributed generation (DG) system planning and optimisation techniques: Comparison of numerical and mathematical modelling methods," Renewable \& Sustainable Energy Reviews, vol. 67, pp. 531-573, 2017.

[102] J.-H. Cho, Y. Wang, I.-R. Chen, K. S. Chan, and A. Swami, "A survey on modeling and optimizing multi-objective systems," IEEE Communications Surveys \& Tutorials, vol. 19, no. 3, pp. 1867-1901, 2017.

[103] Z. Ding, W. Gong, S. Li, and Z. Wu, "System dynamics versus agent-based modeling: a review of complexity simulation in construction waste management," Sustainability, vol. 10, no. 7, p. 2484, 2018.

[104] H.-K. Ringkjøb, P. M. Haugan, and I. M. Solbrekke, "A review of modelling tools for energy and electricity systems with large shares of variable renewables," Renewable \& Sustainable Energy Reviews, vol. 96, pp. 440-459, 2018.

[105] D. Olsthoorn, F. Haghighat, and P. A. Mirzaei, "Integration of storage and renewable energy into district heating systems: A review of modelling and optimization," Integration of Storage and Renewable Energy into District Heating, vol. 136, pp. 49-64, 2016.

[106] P. S. Georgilakis and N. D. Hatziargyriou, "A review of power distribution planning in the modern power systems era: models, methods and future research," Electric Power Systems Research, vol. 121, pp. 89-100, 2015. 
[107] L. M. H. Hall and A. R. Buckley, "A review of energy systems models in the UK: Prevalent usage and categorisation," Applied Energy, vol. 169, pp. 607-628, 2016.

[108] G. A. Shirali, I. Mohammadfam, and V. Ebrahimipour, "A new method for quantitative assessment of resilience engineering by PCA and NT approach: A case study in a process industry," Reliability Engineering \& System Safety, vol. 119, pp. 88-94, 2013.

[109] S. E. van der Merwe, R. Biggs, and R. Preiser, "A framework for conceptualizing and assessing the resilience of essential services produced by socio-technical systems," Ecology and Society, vol. 23, no. 2, p. 12, 2018.

[110] T. M. Shortell, Ed., INCOSE Systems Engineering Handbook: A Guide for System Life Cycle Processes and Activities, John Wiley\& Sons, 4th edition, 2015.

[111] N. M. El-Gohary and T. E. El-Diraby, "Domain ontology for processes in infrastructure and construction," Journal of Construction Engineering and Management, vol. 136, no. 7, pp. 730-744, 2010.

[112] A. Levenchuk, "Sistemnaya kholarkhiya," Sistemnoye myshleniye, Izdatel'skiye resheniya, pp. 89-117, 2018.

[113] "The Resilience of the Electricity System, Science and Technology Committee of the House of Lords," https://publications.parliament.uk/pa/ld201415/ldselect/ldsctech/121/12102.htm, 2015.

[114] H. Treasury, The Green Book: Central Government Guidance on Appraisal and Evaluation, HM Treasury, London, UK, 2018.

[115] G. Wilson, T. M. Wilson, N. I. Deligne, and J. W. Cole, "Volcanic hazard impacts to critical infrastructure: A review," Journal of Volcanology and Geothermal Research, vol. 286, pp. 148-182, 2014. 


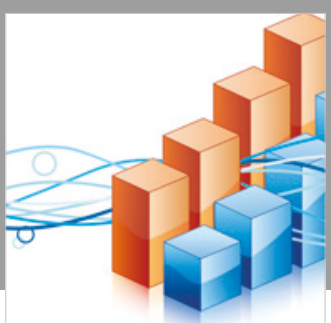

Advances in

Operations Research

\section{-n-m}
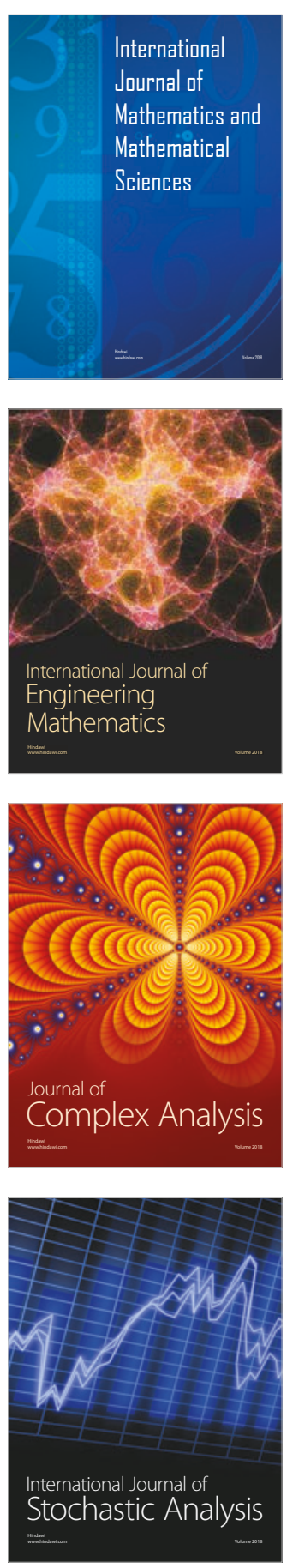
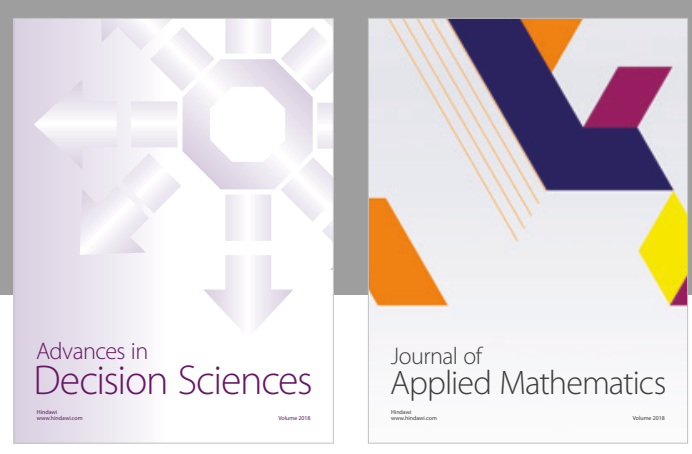

Journal of

Applied Mathematics
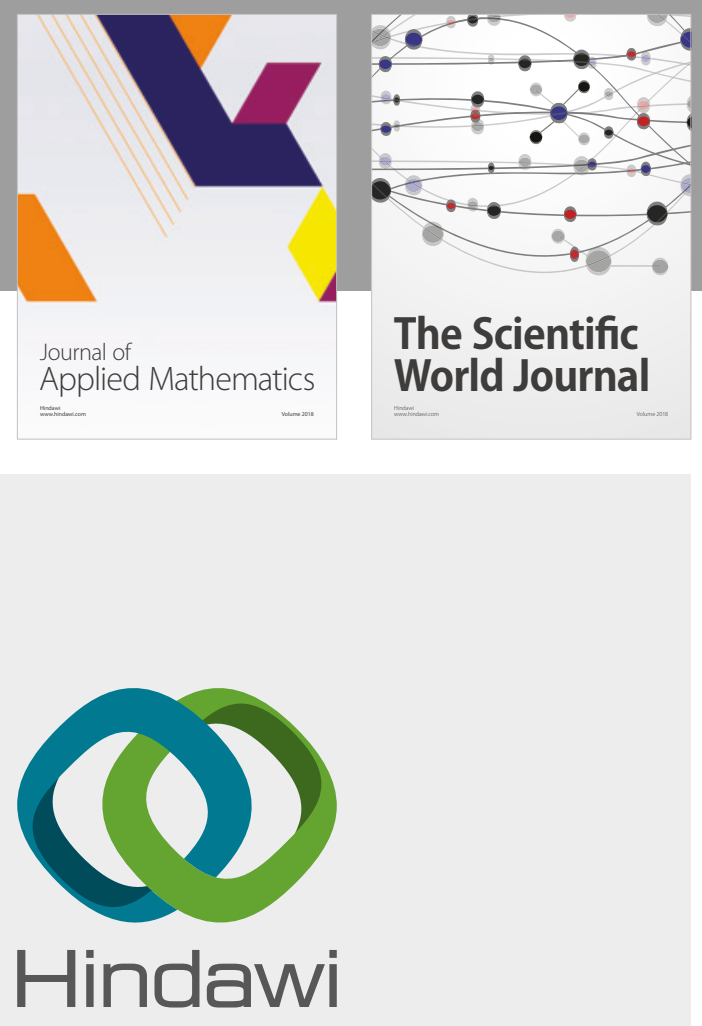

Submit your manuscripts at

www.hindawi.com

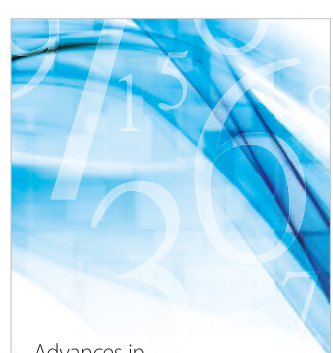

Advances in
Numerical Analysis
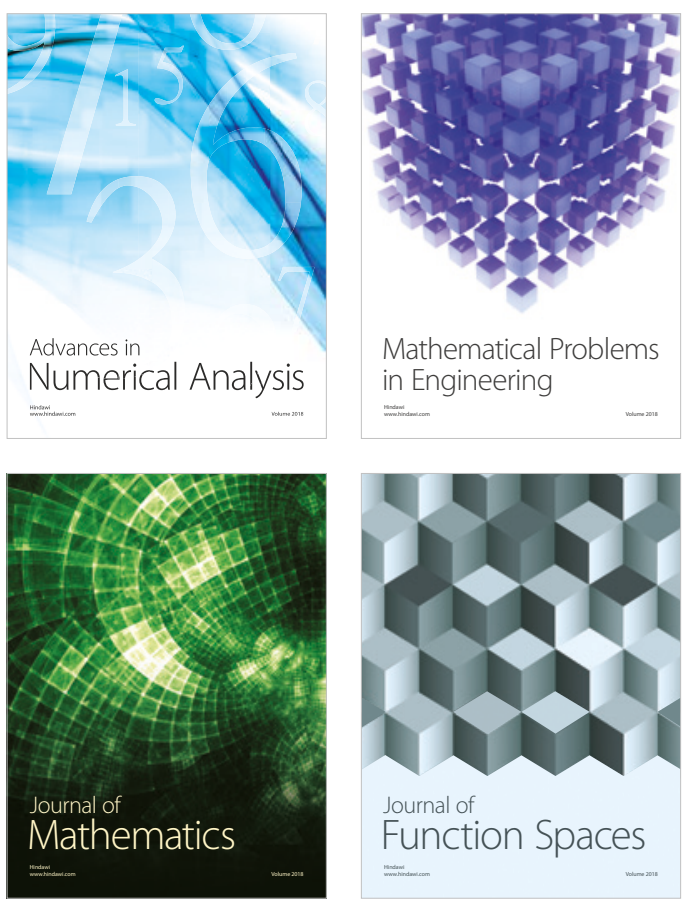

Mathematical Problems in Engineering

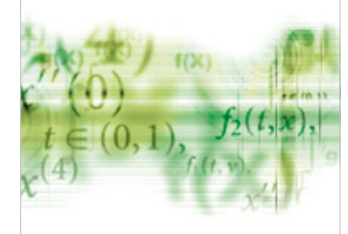

International Journal of

Differential Equations

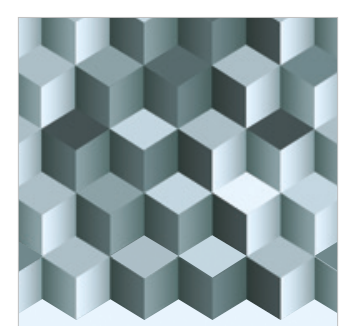

Journal of

Function Spaces
The Scientific

World Journal

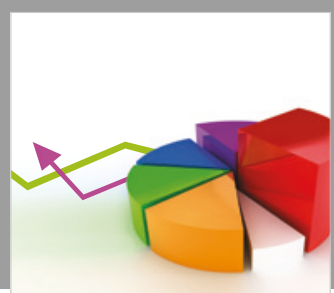

Journal of

Probability and Statistics
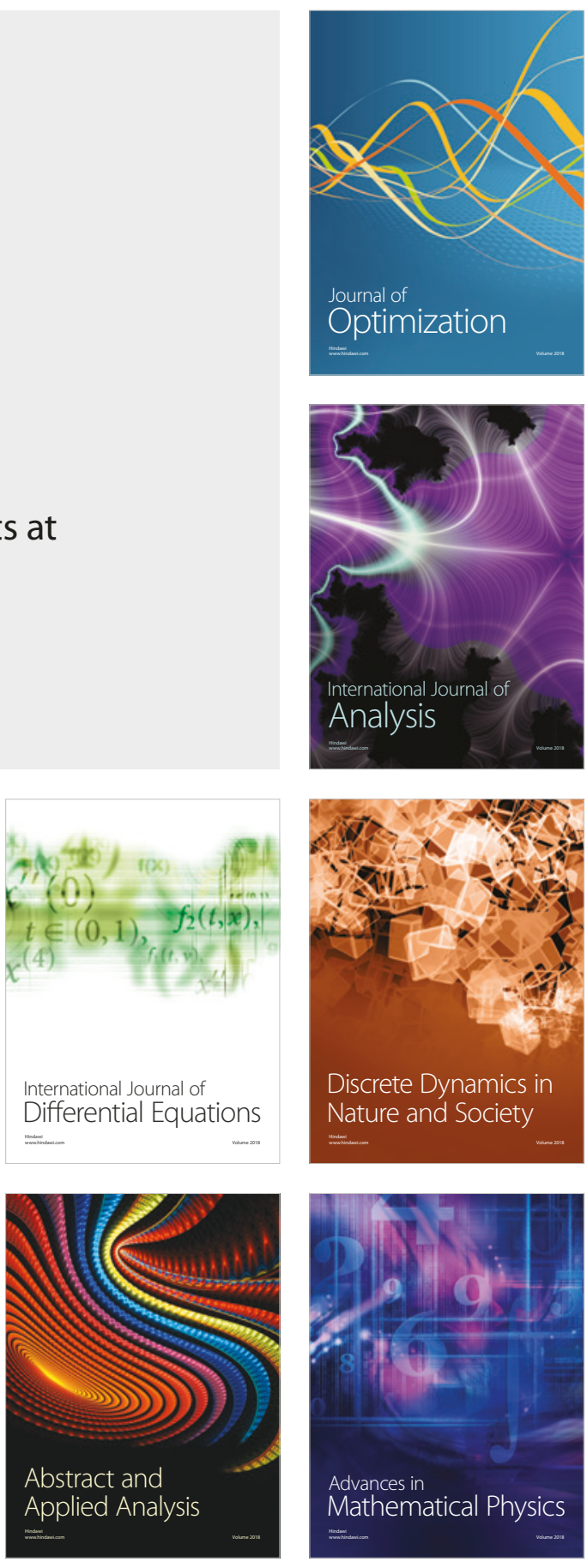